\title{
IMPLEMENTASI SISTEM UJIAN BERBASIS ONLINE PADA UJIAN ESAI BAHASA INDONESIA
}

\author{
Rohayati $^{1}$, Ratnawati ${ }^{2}$, Asri Kunda ${ }^{3}$ \\ Komputerisasi Akuntansi STMIK AKBA ${ }^{1}$, Sistem Informasi STMIK AKBA ${ }^{2}$, \\ Sistem Informasi STMIK DIPANEGARA ${ }^{3}$ \\ Email: rohayati@akba.ac.id ${ }^{1,}$ ratnawati@akba.ac.id ${ }^{2,}$ kundaasri@yahoo.com³
}

\begin{abstract}
ABSTRAK
Penelitian ini bertujuan untuk mengimplementasikan aplikasi sistem ujian berbasis online pada ujian esai bahasa Indonesia.Deangan mengimplementasikan sistem ini dapat meminimalkan unsur subjektifitas dosen dalam memberi penilaian, dapat mengurangi penggunaan kertas dan pelaksanaan ujian dapat dilakukan kapan dan dimana saja sesuai dengan kesepakatan antara dosen dan mahasiswa.Sistem ujian berbasis online pada ujian esai bahasa Indonesia dibagun dengan menggunakan metode waterfall dengan tahapan; analisis, desain, implementasi, pengujian sistem sampai pada tahap pemeliharaan. Sistem akan diimplementasikan atau dikodekan dengan menggunakan bahasa pemrograman PHP. Pada pengkodean sistem digunakan aplikasi text editor Sublime.Untuk melihat hasil pengkodean sedikit demi sedikit akan ditampilkan dengan browser Chrome.Tahapan implementasi dimulai dari halaman login, pembuatan soal ujian dan penambahan soal ujian, pelaksanaan ujian, pemeriksaan hasil ujian, penentuan hasil ujian, kustomisasi profil.Aplikasi sistem ujian berbasis online pada ujian esai bahasa Indonesia ini dapat mengurangi waktu terbuang dalam penilaian jawaban mahasiswa dan memberikan penilaian yang lebih objektif dengan rata-rata akurasi 90,3\% dari 170 jawaban yang diproses.
\end{abstract}

Kata kunci: Implemetasi, sistem penilaian otomatis, Waterfall, efektif, efisien

\section{PENDAHULUAN}

Evaluasi hasil belajar merupakan komponen yang sangat penting dalam proses pembelajaran, karena hasil evaluasi pembelajarandapat dijadikan sebagai salah satu indikator untuk mengukur tingkat pemahaman penguasaan materi pelajaran yang telah diberikan kepada peserta didik.

Ada berbagai bentuk evaluasi hasil belajar.Salah satunya yaitu dengan ujian esai.Ujian esai dianggap sebagai bentuk evaluasi belajar yang sangat tepat, karena melibatkan kemampuan siswa dalam mengingat, mengorganisasikan, mengekspresikan dan mengintegrasikan gagasan yang dimiliki siswa terkait dengan soal esai tersebut.Menurut Ngalim Purwanto (1991:35), dalam test dituntut kemampuan peserta didik untuk benarbenar memahami pertanyaan dan merealisasikan gagasannya melalui bahasa tulisan, sehingga tipe esai test lebih bersifat power test. Bentuk-bentuk pertanyaannya biasanya meminta pada peserta didik untuk menjelaskan, membandingkan, menginterpretasikan dan mencari perbedaan.Semua bentuk pertanyaan tersebut mengharapkan agar peserta didik menunjukkan pengertian mereka terhadap materi yang dipelajari.Tes esai digunakan untuk mengatasi kelemahan daya ukur soal 
objektif yang terbatas pada hasil belajar rendah. Soal tes bentuk ini cocok untuk mengukur hasil belajar yang level kognisinya lebih dari sekedar memanggil informasi, karena hasil belajar yang diukur bersifat kompleks (Silverius, 1991:1).

Ujian esai biasanya banyak diterapkan di pendidikan tingkat tinggi, sebagaimana yang diterapkan di STMIK AKBA.Akan tetapi, dalam penerapannya dosen memerlukan waktu yang banyak untuk memeriksa jawaban esai, semakin banyak jumlah ujian dan banyaknya jumlah mahasiswa yang mengikuti ujian, maka semakin banyak jumlah ujian yang dikoreksi oleh dosen.Hal ini menyebabkan kualitas penilaian menurun dan terkadang penilaian tidak bersifat objektif lagi.

Salah satu kesulitan penilaian ujian esai adalah subjektivitas.Banyak peneliti menyatakan bahwa sifat subjektif dari penilaian esai menyebabkan variasi penilaian di kelas yang diberikan oleh penilai manusia yang berbeda, yang dirasakan oleh siswa sebagai sumber ketidakadilan. Selanjutnya penilaian esai adalah kegiatan memakan waktu (Valenti, Neri, \& Cucchiarelli, 2003).

Beberapa peneitian telah dilakukan untuk mengatasi masalah penilaian ujian esai dengan membangun sistem penilaian ujian esai secara otomatis. Para peneliti menerapkan metode yang berbeda-beda dalam masalah ini, diantaranya penelitian Bahri (2014), Astutik, Cahyani, \& Sophan (2014), Fitri \& Asyikin (2015).

Penelitian Astutik, Cahyani, \& Sophan(2014)menunjukkan bahwa penilaian menggunakan algoritma winnowing menghasilkan akurasi yang lebih baik pada teks jawaban yang memiliki struktur kalimat jawaban yang sama dengan kunci jawaban yaitu sebesar
75-80\%. Namun, hasil penilaian degan algoritma ini sangat dipengaruhi oleh nilai n-gram yang digunakan, semakin kecil nilai n-gram yang digunakan maka akan semakin tidak peka algoritma winnowing mengukur kesamaan jawaban dengan kunci jawaban. Penelitian Fitri dan Asyikin (2015) menujukkan bahwa sistem penilaian esai otomatis menggunakan metode cosine similarity berjalan dengan baik untuk ujian esai dalam bahasa Inggris dengan kesesuaian nilai sistem dengan nilai yang diberikan oleh pengajar adalah rata-rata $89,48 \%$.

Peneltian ini akan mengimplementasikan aplikasi sistem pemeriksaan otomatis berbasis web yang telah dibagun dengan dengan metode pengembagan waterfall dan menerapkan cosine similarity.

\section{LANDASAN TEORI}

\section{A. Evaluasi Hasil Belajar}

Penilaian hasil belajar menurut Sudjana (2005) merupakan proses pemberian nilai terhadap hasil belajar yang dicapai siswa dengan kriteria tertentu. Hal ini menunjukkan bahwa hasil belajar siswa merupakan objek penilaian.Penilaian dilakukan dengan menggunakan alat penilaian yang merupakan alat ukur. Fungsi penilaian menurut Sudjana sebagai alat untuk mengetahui tercapai atau tidaknya tujuan instruksional, umpan balik bagi perbaikan proses belajar mengajar dan dasar dalam penyusunan laporan kemajuan belajar siswa kepada orang tuanya. Fungsi penilaian menurut Jihad dan Haris (2008) sebagai pemantauan kinerja komponen-komponen kegiatan proses belajar mengajar dalam mencapai tujuan yang diharapkan dalam proses belajar mengajar. Fungsi penilaian dapat 
disimpulkan untuk memantau dan mengetahui perkembangan komponen dalam kegiatan belajar dan mengajar sehingga dapat diambil tindakan selanjutnya sesuai dengan tujuan yang ditentukan.

Tujuan penilaian menurut Sudjana (2005)yaitu untuk: 1) mendeskripsikan kecakapan belajar siswa, 2) mengetahui keberhasilan proses pendidikan dan pengajaran di sekolah, 3) menentukan tindak lanjut hasil penilaian, 4) memberikan pertanggungjawaban dari pihak sekolah ke pihak yang berkepentingan. Kecakapan belajar siswa yaitu untuk mengetahui kelebihan dan kekurangan siswa pada mata pelajaran dan level kemampuan siswa dibandingkan dengan siswa lain. Keberhasilan proses pendidikan dan pengajaran di sekolah yaitu untuk mengetahui keefektifan komponen pendidikan dalam mencapai tujuan yang telah ditentukan. Tindak lanjut hasil penilaian yaitu tindakan berupa penyempurnaan proses belajar mengajar maupun merubah hal-hal yang dirasa kurang tepat. Pertanggungjawaban kepada pihak yang berkepentingan yaitu berupa laporan keberhasilan pendidikan maupun hambatan yang terjadi dalam proses pendidikan.

\section{B. Penilaian Tes}

Penilain tes terdiri dari tes objektif dan tes subjektif.tes subjektif (tes esai)merupakan tes yang banyak digunakan dalam menilai hasil belajar. Tes objektif dipilih karena cakupan materi pelajaran yang luas dan mudah dalam melakukan penilaian. Bentuk soal objektif menurut Sudjana (2005:44) antara lain: 1) jawaban singkat, 2) benar-salah, 3) menjodohkan, 4) pilihan ganda. Bentuk tes selain jawaban singkat dalam soal telah tersedia kemungkinan jawaban yang dapat dipilih.Kelebihan model tes esai menurut Sudjana (2005) adalah sebagai berikut: a) dapat mengukur proses mental yang tinggi atau aspek kognitif tingkat tinggi; b) dapat mengembangkan kemampuan berbahasa, baik lisan maupun tulisan dengan baik dan benar sesuai dengan kaidah-kaidah bahasa; c) dapat melatih kemampuan berpikir teratur atau penalaran, yakni berpikir logis, analitis dan sistematis; d) mengembangkan kemampuan pemecahan masalah (problem solving); e) adanya keuntungan teknis seperti mudah dalam penyusunan soal, guru dapat langsung melihat proses berpikir siswa. Kelemahan soal tes esai antara lain: a) sampel tes sangat terbatas sebab dengan tes ini tidak mungkin dapat menguji semua bahan; b) sifatnya sangat subjektif, baik dalam menanyakan, membuat pertanyaan maupun cara memeriksanya; c) tes ini biasanya kurang reliabel, mengungkap aspek yang terbatas, pemeriksaannya memerlukan waktu lama.

\section{Pengujian Berbasis Komputer}

Tes esai berbantuan komputer mempunyai dua fungsi utama yaitu untuk membuat soal esai dan menilai jawaban esai soal.Jawaban esai dalam melakukan koreksinya menggunakan metode string similarity yaitu dengan membandingkan jawaban soal dengan jawaban yang ada pada bank soal.

Software Model Tes Esai Berbantuan Komputer dalam memberi skor berdasarkan perbandingan text kunci jawaban dan jawaban. Perbandingan text menurut Gomaa dan Fahmy (2012) dibagi menjadi dua yaitu: 1) String based Similarity, merupakan penentuan kesamaan kata berdasarkan urutan huruf dan komposisi huruf, String based similarity dibagi menjadi 13 jenis yang terdiri dari 6 character based distance measures dan 7 term based 
distance measures; 2) Corpus Based Similarity, merupakan penentuan persamaan kalimat dengan mencari sinonim dari tiap kata dari database (library).

Character based distance measures diantaranya: 1) Damerau-Lavenshtein distance, 2) Jaro algorithm, 3) Jaro-Winkler distance, 4) Needleman-Wunsch algorithm, 5) Smith-Waterman algorithm, 6) N-Gram similarity algorithm. Term based distance measures diantarnya: 1) Block Distance, 2) Cosine similarity, 3) Dice's coefficient,4) Euclideandistance, 5) Jaccard similarity, 6) Matching coefficient, 7) Overlap coefficient. Corpus based similarity diantaranya: 1) Latent semantic analysis, 2) Explicit semantic analysis, 3) Pointwise mutual information, 4) Extracting DIS tributionally similar word using CO-occurrences (DISCO).

\section{Tahapan Pengembangan Sistem dengan Metode Waterfall}

Metode waterfall (air terjun) memacu tim pengembang untuk merinci apa yang seharusnya perangkat lunak lakukan (mengumpulkan dan menentukan kebutuhan sistem) sebelum sistem tersebut dikembangkan. Kemudian, model ini memungkinkan pemecahan misi pengembangan yang rumit menjadi beberapa langkah logis (desain, kode, pengujian, dan seterusnya) denga beberapa langkah yang pada akhirnya akan menjadi produk akhir yang siap pakai (Simarmata, 2010).

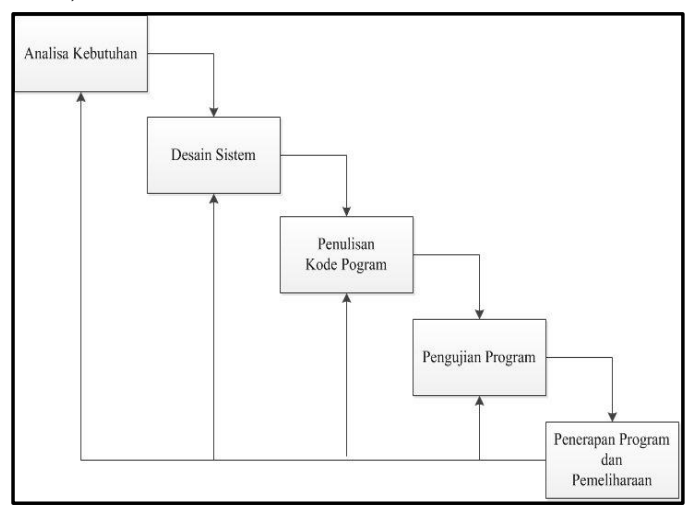

Gambar 1. Alur Metode Waterfall
Dalam pengembangannya, metode waterfall memiliki beberapa tahapan yang berurut yaitu: Requirement (analisis kebutuhan), System design (desain sistem), Coding (pengkodean), Testing (pengujian), Penerapan Program dan pemeliharaan.

\section{III.HASIL DAN PEMBAHASAN}

Implementasi aplikasi sistem ujian berbasis online pada ujian esai bahasa Indonesia melalui beberapa tahapan yaitu; tahapan login, pembuatan soal ujian dan penambahan soal ujian, pelaksanaan ujian, pemeriksaan hasil ujian, penentuan hasil ujian (pengumuman hasil ujian), kustomisasi profil.

\section{A. Login}

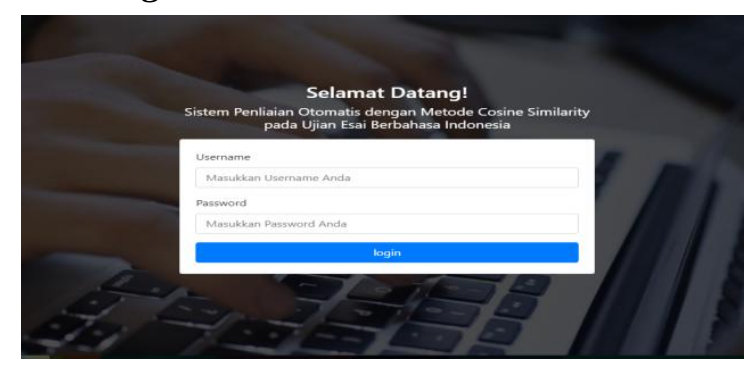

Gambar 2. Login Sistem

User yang ingin menggunakan sistem login terlebih dahulu.Data yang dimasukkan berupa username dan password.Secara default username dan password merupakan nomor induk dari user tersebut, tapi dapat diganti pada menu profil yang disediakan.

\section{B. Pembuatan Soal Ujian}

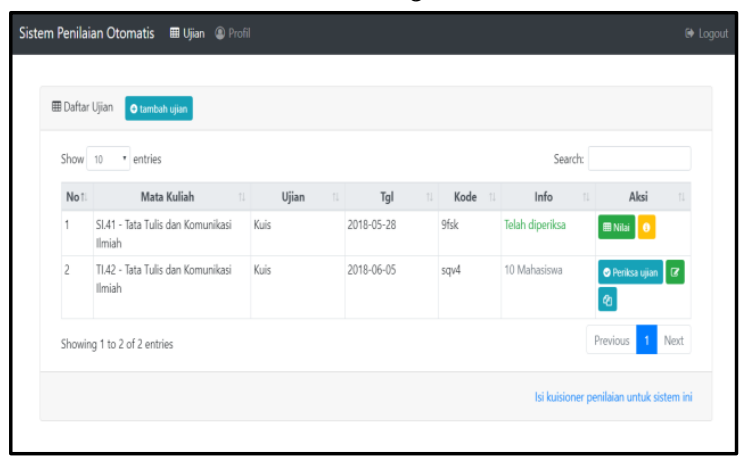

Gambar 3. Beranda Dosen 
Gambar 3 merupakan tampilan beranda untuk dosen, data yang ditampilkan berupa daftar ujian yang pernah dibuat. Untuk membuat soal ujian baru, klik pada tombol tambah ujian, maka akan tampil form tambah ujian seperti pada gambar 4 .

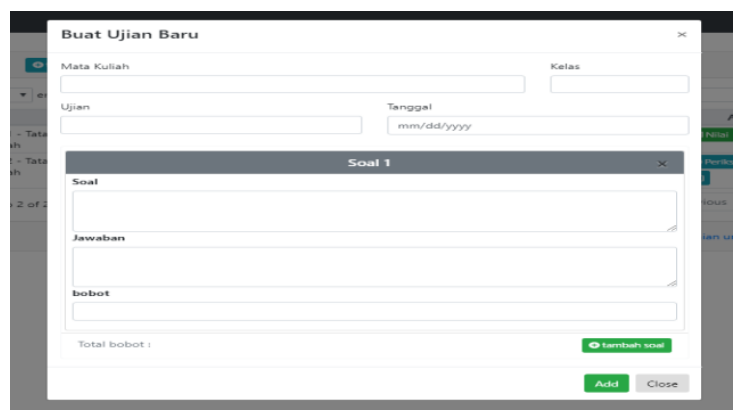

Gambar 4. Form Pembuatan Soal Ujian

User mengisi form yang ditampilkan, untuk menambahkan soal klik tombol tambah soal, maka akan muncul form isian soal baru. Perlu diingat bahwa total bobot harus tepat sebesar 100, jika tidak maka ujian tidak akan dapat disimpan. Jika semua isian telah diisi silahkan klik tombol Add.

\section{Pelaksanaan Ujian}

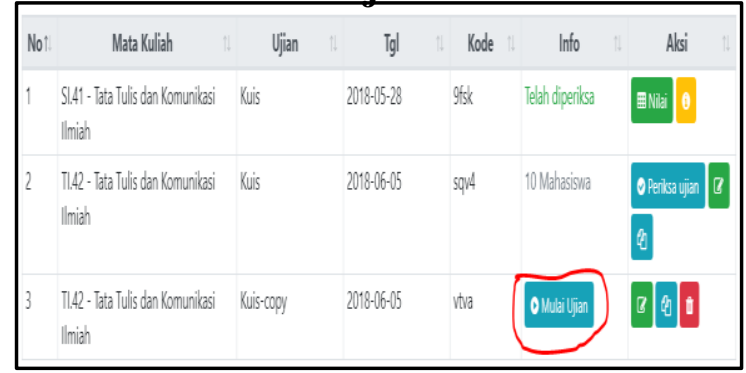

Gambar 5. Daftar Ujian

Dosen dapat mengklik tombol mulai ujian jika ingin agar mahasiswa mulai mengerjakan soal-soal yang telah dibuat.Setelah itu dosen menginformasikan kode ujian kepada mahasiswa agar mahasiswa dapat membuka dan mengerjakan ujian yang telah dibuat sebelumnya. Setelah ujian dimulai, sistem akan menampilkan jumlah mahasiswa yang telah mengerjakan ujian yang berada pada kolom info.

\section{Pemeriksaan Ujian}

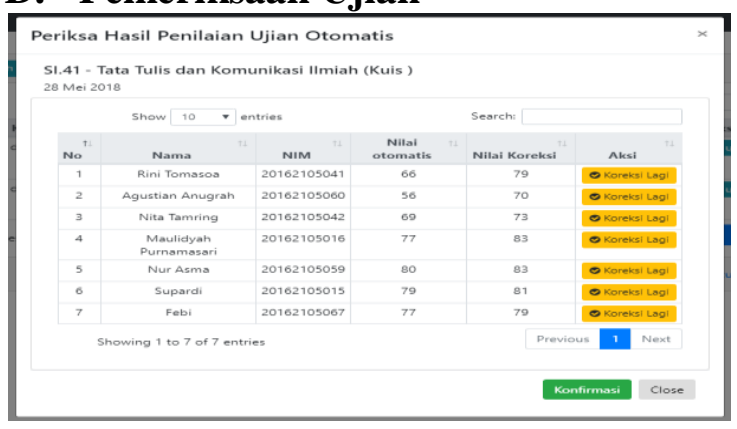

Gambar 6. Pemeriksaan Ujian

Untuk memeriksa ujian, dosen dapat mengklik tombol periksa ujian yang ada pada gambar 6. maka sistem akan menghitung nilai ujian mahasiswa secara otomatis, lalu menampilkan hasilnya seperti pada gambar 7Error! Reference source not found.. Jika nilai otoamtis yang dihasilkan dirasa masih kurang tepat, dosen dapat mengoreksi nilai otomatis

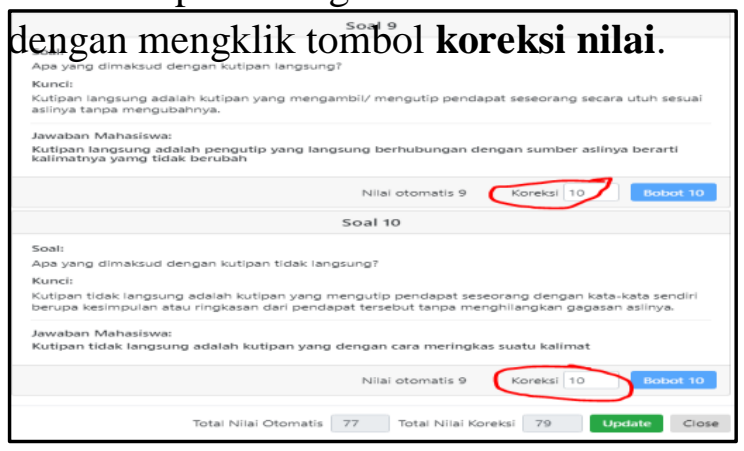

Gambar 7. Form Koreksi Nilai

\section{E. Pengerjaan Ujian}

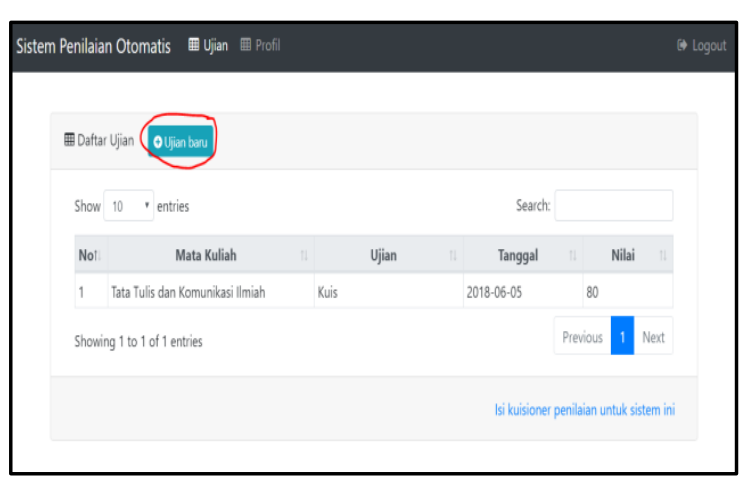

Gambar 8. Beranda Mahasiswa 
Gambar 8. merupakan tampilan awal saat mahasiswa login ke sistem, daftar ujian yang pernah dikerjakan ditampilkan beserta nilai hasil ujian yang didapatkan.Untuk mulai mengerjakan ujian baru, mahasiswa dapat mengklik tombol ujian baru.

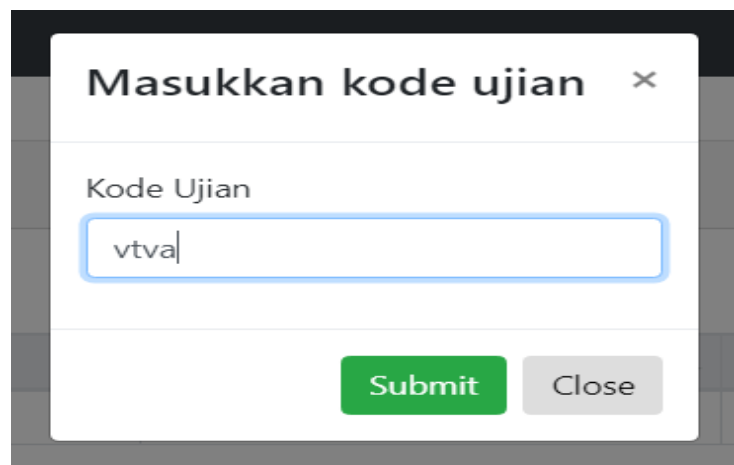

Gambar 9. Form Cari Ujian

Mahasiswa memasukkan kode ujian yang telah diberikan oleh dosen pada form yang tersedia, lalu mengklik tombol submit. Jika kode ujian bernar maka daftar soal ujian akan ditampilkan seperti pada gambar 10.

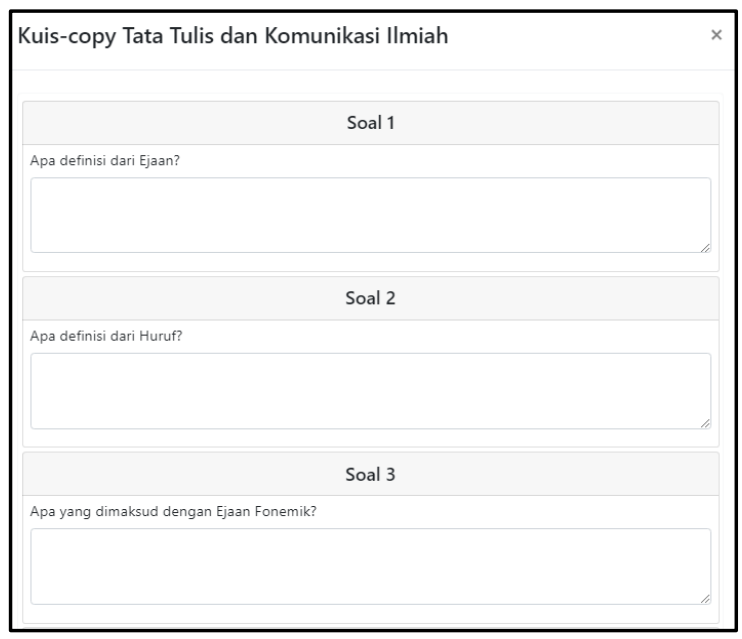

Gambar 10. Daftar Soal Ujian

Mahasiswa dapat menjawab soalsoal ujian dengan mengisi form yang disediakan. Jika seluruh soal telah dikerjakan, mahasiswa dapat mengklik tombol submit yang ada di bagian bawah.
F. Kustomisasi Profil

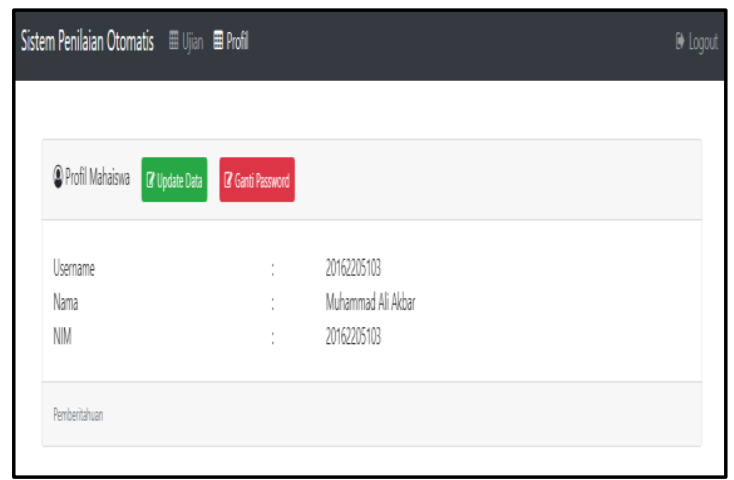

Gambar 11. Kustomisasi Profil

Pada menu kustomisasi profil terdapat 2 pilihan, yaitu update data dan ganti password. Untuk tombol update data, user dapat mengubah username, nama dan nomor induk seperti pada gambar 12 .

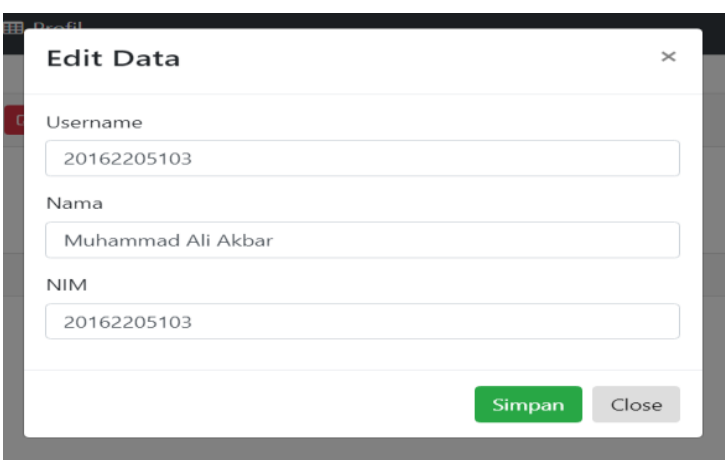

Gambar 12. Edit Data Personal

Gambar 12. merupakan tampilan form untuk menperbaharui data user. Jika data sudah diperbaharui, user dapat mengklik tombol simpan, jika tidak ingin mengubah data, silahkan klik tombol close.

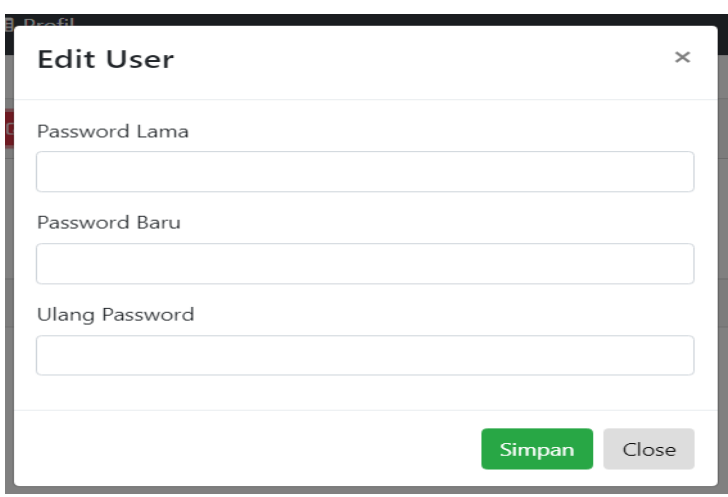

Gambar 13. Ganti Password 
Gambar 13. merupakan tampilan form untuk mengganti password.User harus memasukkan password lama secara bernar, dan mengulang password baru sebanyak 2 kali agar tidak terjadi kesalahan penginputan password. Jika telah selesai silahkan klik tombol simpan, maka user akan diminta untuk login kembali.

\section{KESIMPULAN}

1. Aplikasi sistem Ujian berbasis online pada soal esai berbahasa Indonesia dapat digunakan sebagai salah satu alternatif pelasanaan ujian secara online yang efektif dan efisien. Sistem ini juga cukup baik untuk mengatasi penilaian yang kurang obyektif yang menurut beberapa mahasiswa sebagai sumber ketidakadilan.

2. Pada implementasi sistem ujian berbasis online pada soal esai berbahasa Indonesia ini menunjukkan sistem memiliki kemampuan untuk mengukur kemiripan teks berdasarkan term-nya. Penerapan sistem ini dianggap sangat baik dan memberikan pengaruh positif, karena memiliki rata-rata akurasi penilaian yang tinggi sebesar $90,3 \%$ dari 170 jawaban yang diproses.

\section{Daftar Pustaka}

Adiwidya, B. M. (2009). Algoritma Levenshtein Dalam Pendekatan Approximate String Matching. Bandung: Institut Teknologi Bandung.

Amin, F. (2012). Sistem Temu Kembali Informasi dengan Metode Vector Space Model. Jurnal Sistem Informasi Bisnis.
Arief, M. R. (2011). Pemrograman Web Dinamis Menggunakan PHP dan MySQL. Yogyakarta: Andi.

Astutik, S., Cahyani, A. D., \& Sophan, M. K. (2014). Sistem Penilaian Esai Otomatis Pada E-Learning Dengan Algoritma Winnowing. Jurnal Informatika. doi:10.9744/informatika.12.2.47-52

Bahri, S. (2014). Penilaian Otomatis Ujian Essay Online berbasis Algoritma Rabin Karp. SWABUMI, I.

Fitri, R., \& Asyikin, A. N. (2015). Aplikasi Penilaian Ujian Essay Otomatis Menggunakan Metode Cosine Similarity. Poros Teknik.

Galandi, F. (2016). Metode Waterfall: Definisi, Tahapan, Kelebihan dan Kekurangan. Diambil 25 Maret 2018, dari http://www.pengetahuandanteknologi .com/2016/09/metode-waterfalldefinisi-tahapan.html

Goma, W. H., \& Fahmi, A. A. (2012). Short Answer Grading Using String Similarity and Corpus Based Similarity. International Journal of Advanced Computer Science and Application.

(2013). A Survey of Text Similarity Approaches. International Journal of Computer Applications. doi:10.5120/11638-7118

Hadi, S. (2013). Pengembangan Computerized Adaptive Test Berbasis Web. Yogyakarta: Aswaja Pressindo.

Ingwersen, P. (1992). Information Retrieval Interaction. Information Processing \& Management. London: Taylor Graham Publishing. doi:10.1016/0306-4573(93)90108-P

Jihad, A., \& Haris, A. (2008). Evaluasi Pembelajaran. Yogyakarta: Multi Pressindo. 
Kristanto, A. (2008). Perancangan Sistem Informasi dan Aplikasinya. Yogyakarta: Gava Media.

Manning, C. D., Ragahvan, P., \& Schutze, H. (2009). An Introduction to Information Retrieval. Information Retrieval. doi:10.1109/LPT.2009.2020494

Nugroho, B. (2004). Aplikasi Pemrograman Web Dinamis dengan $P H P$ dan MySQL. YOgyakarta: Gava Media.

Rownlands, I. (1986). Text Retrieval : an Introduction. London: Taylor Graham.

Salton, G. (1989). Automatic Text Processing, The Transformation, Analysis, and Retrieval of information by computer. USA: Addison - Wesly Publishing Company, Inc.

Simarmata, J. (2010). Rekayasa Perangkat Lunak. Yogyakarta: Penerbit Andi.

Sudjana, N. (2005). Penilaian Hasil Proses Belajar Mengajar. Bandung: Remaja Rosdakarya.

Valenti, S., Neri, F., \& Cucchiarelli, A. (2003). An Overview of Current Research on Automated Essay Grading. Journal of Information Technology Education. Diambil dari http://citeseerx.ist.psu.edu/viewdoc/d ownload?doi=10.1.1.101.5757\&amp; rep=rep1\&amp;type $=$ pdf 